\title{
A infância e a educação infantil no campo: como anda o diálogo?
}

\author{
CHILDHOOD AND A CHILDHOOD EDUCATION IN THE FIELD: HOW DOES THIS
}

DIALOGUE WALK?

\author{
Cláudia Celeste Lima Costa Menezes (iD-
}

\section{Resumo}

A pesquisa intitulada A Infância e a Educação Infantil no Campo: como anda este diálogo? tem como objetivo central analisar como se encontra o diálogo entre a infância, os saberes e as práticas vivenciadas na Educação Infantil do Campo, partindo do seguinte questionamento: Existe uma relação efetiva e congruente entre a infância, os saberes e a prática pedagógica de Educação Infantil do Campo que assegure a qualidade do processo educativo e a formação do cidadão do campo? 0 estudo evidencia a infância, os marcos legais, destacando os percursos, os avanços e os entraves da legislação brasileira e das políticas públicas para a Educação Infantil do Campo revelando os percalços enfrentados para o desenvolvimento de uma prática pedagógica democrática e de qualidade que valorize a infância no campo. A pesquisa tem um caráter qualitativo, fundamentada na abordagem fenomenológica e no método etnográfico, tendo como opção metodológica o estudo de caso. Esta pesquisa teve como locus uma instituição educativa de um município baiano, situada no campo. Foram aplicados os instrumentos da observação, entrevista semi-estruturada e grupo focal. Os dados coletados foram analisados através da interpretação da análise do conteúdo, apresentando resultados significativos para o desenvolvimento da Educação Infantil do município e região. Os estudos e as reflexões realizadas possibilitaram afirmar que existe um diálogo tímido entre a infância, os saberes e as práticas pedagógicas, decorrentes da não implementação das políticas públicas, fator que compromete a qualidade e o desenvolvimento da Educação Infantil do Campo.

Palavras-chave: Educação Infantil do Campo. Infância. Saberes e Práticas.

\section{Abstract}

The research entitled Childhood and Early Childhood Education in the Countryside: how is this dialogue going? aims to analyze how the dialogue between childhood, knowledge and

a Professora da Universidade Estadual de Santa Cruz/ DCIE-UESC, BA: Ilhéus. Doutora em educação. E-mail: cclcmenezes@uesc.br

Rev. Caminhos da Educação: diálogos, culturas e diversidades, Teresina, v. 1, n. 3, p. 143165, jan/abr. 2020 
practices experienced in Early Childhood Education in the Countryside is based on the following question: There is an effective and congruent relationship between childhood, knowledge and pedagogical practice in Early Childhood Education do Campo that ensures the quality of the educational process and the training of the rural citizen? The study highlights childhood, legal frameworks, highlighting the paths, advances and obstacles of Brazilian legislation and public policies for Early Childhood Education in the Countryside, revealing the obstacles faced for the development of a democratic and quality pedagogical practice that values the childhood in the countryside. The research has a qualitative character, based on the phenomenological approach and the ethnographic method, with the case study as a methodological option. This research had as locus an educational institution in a municipality in Bahia, located in the countryside. Observation instruments, semistructured interviews and focus groups were applied. The collected data were analyzed through the interpretation of the content analysis, showing significant results for the development of Early Childhood Education in the city and region. Studies and reflections made it possible to affirm that there is a timid dialogue between childhood, knowledge and pedagogical practices, resulting from the non-implementation of public policies, a factor that compromises the quality and development of Early Childhood Education in the countryside.

Keywords: Early Childhood Education. Childhood. Knowledge and Practices.

\section{Resumen}

La investigación titulada Educación de la primera infancia y la infancia en el campo: cómo va este diálogo? tiene como objetivo analizar cómo el diálogo entre la infancia, el conocimiento y las prácticas experimentados en la Educación Infantil en el Campo se basa en la siguiente pregunta: Existe una relación efectiva y congruente entre la infancia, el conocimiento y la práctica pedagógica en la Educación Infantil Qué Campo asegura la calidad del proceso educativo y la formación del ciudadano rural? El estudio destaca la infancia, los marcos legales, destacando los caminos, avances y obstáculos de la legislación brasileña y las políticas públicas para la Educación de la Primera Infancia en el Campo, revelando los obstáculos enfrentados para el desarrollo de una práctica pedagógica democrática y de calidad que valore el infancia en el campo. La investigación tiene un carácter cualitativo, basado en el enfoque fenomenológico y el método etnográfico, con el estudio de caso como una opción metodológica. Esta investigación tuvo como sede una institución educativa en un municipio de Bahía, ubicado en el campo. Se aplicaron instrumentos de observación, entrevistas semiestructuradas y grupos focales. Los datos recopilados se analizaron a través de la interpretación del análisis de contenido, mostrando resultados significativos para el desarrollo de la Educación Infantil en la ciudad y la región. Los estudios y las reflexiones permitieron afirmar que existe un diálogo tímido entre la infancia, el conocimiento y las prácticas pedagógicas, como resultado de la no implementación de las políticas públicas, un factor que compromete la calidad y el desarrollo de la educación de la primera infancia en el campo.

Palabras clave: Educación de la primera infancia. Infancia Conocimientos y prácticas. 


\section{Introdução}

A complexidade da Educação Infantil aliada à multidimensionalidade do mundo globalizado tem impulsionado os pesquisadores da área educacional a estudar e investigar a educação das crianças pequenas em seus diferentes espaços. O processo de globalização vivenciado nas últimas décadas tem provocado desestabilizações em todos os setores da vida humana, assinalando fortes mudanças culturais, econômicas, sociais, políticas e educacionais, levando as instituições, a estabelecer novas relações com o conhecimento científico, com a sociedade e com a educação. Discutir a infância, os saberes e a prática pedagógica da Educação Infantil do Campo é possibilitar um novo olhar para a realidade educacional do campo, visualizando mudanças sociais significativas e a construção de um conhecimento que oportunize a formação de verdadeiros cidadãos.

No que diz respeito às políticas públicas, as Diretrizes Nacionais para a Educação Infantil e as Diretrizes Operacionais para a Educação Básica nas Escolas do Campo constituem-se em dois documentos legais que buscam legislar e apresentar condutas pedagógicas para assegurar educação com qualidade e identidade a Educação Infantil do Campo. Apesar desses avanços, percebe-se, ainda, que permeiam as instituições infantis os resquícios de todas as contradições apresentadas durante séculos. Neste cenário, parece-nos fundamental a problemática central desta pesquisa, no sentido de saber se existe uma relação efetiva e congruente entre a infância, os saberes e a prática pedagógica de Educação Infantil do Campo que assegure a qualidade do processo educativo e a formação do cidadão do campo? Visando assegurar a qualidade dos seus resultados, a pesquisa teve como objetivo analisar a infância, os saberes e as práticas vivenciadas no cotidiano escolar da Educação Infantil do Campo e assim verificar como se apresentava a interseção entre os campos político, teórico e prático.

O que nos moveu para realizar essa pesquisa foi à certeza de que seus resultados podem contribuir com a qualidade da educação pública, colaborar com o desenvolvimento educacional e social do município em estudo e região e possibilitar um olhar específico para a Educação Infantil do Campo, segmento da educação 
básica, tão abandonado pelos órgãos competentes e tão carente de políticas públicas e práticas educativas de qualidade.

\section{Discutindo a concepção de infância: do processo histórico à contemporaneidade}

Fazer uma retrospectiva da história da infância nos remete a uma rápida passagem pela Antiguidade e pela Idade Média para compreendermos que a concepção de infância da contemporaneidade é fruto de uma construção histórica, política e socioeconômica e que a aquisição da identidade presente apresenta resquícios de toda uma história social. No mundo romano (Antiguidade), a vida da criança era depositada nas mãos paternas, ou seja, cabia ao pai aceitá-la ou não, se a enjeitasse, seu fim geralmente era a morte, quando menina, se sobrevivesse, iria para os prostíbulos de Roma (MENEZES, 2012).

Na Idade Média, segundo Ariès (1978) o que definia a infância, no contexto europeu, era o aspecto físico, iniciando com o nascimento dos dentes e encerrando aos sete anos de idade. Ao nascer, a criança é denominada de "in-fans", que significa não-fala. Neste período da história, assim que a criança se desenvolvia um pouco e apresentava condições para realizar algumas atividades era logo vista como um adulto em miniatura. A criança era então afastada de seus pais para conviver com outros adultos para ajudá-los nos trabalhos, não havendo nenhuma preocupação com o desenvolvimento infantil e nem com uma formação específica da infância, e sim, com a exploração infantil. Apesar de alguns poucos avanços como não cometer infanticídio e as mães terem o direito de amamentar os seus filhos, os povos germânicos agiam de forma idêntica aos romanos, ou seja, o destino da criança, também, dependia da vontade paterna. Aos pais cabia o direito de adoção, rejeição, compra e venda das crianças (MENEZES, 2012).

No Brasil escravocrata a organização social e econômica é responsável pela divisão da população infantil em dois grupos: a criança da casa-grande e a criança escrava. Essa divisão promove a distância entre as crianças, pois o tratamento dispensado, a inserção social e a educação ministrada são diferenciadas e até mesmo 
negadas. Não era reconhecido o direito à infância para a criança negra, ela não possuía sequer o direito ao leite e aos cuidados maternos, além de ser completamente anulada no meio social. É nesse contexto que se dá o alto índice de mortalidade infantil. Vasconcellos (2005) salienta que, até os cinco anos a criança era considerada um anjo, portanto, para os pais, a morte de uma criança não era vista como tristeza, e sim, como consolo. Contraditoriamente, a criança de cinco a dez anos era vista como "menino-diabo", por causa de suas brincadeiras e traquinagens. A partir dos dez anos, a criança passava a ser considerada como um adulto em miniatura e lhe eram atribuídos diversos tipos de imposições que precisam ser respeitadas e cumpridas (MENEZES, 2012).

A descrição da história demonstra que de 1500 até os anos de 1870 muito pouco se fazia pela infância no Brasil, tanto em atendimento como legalmente (KRAMER, 2006). No século XVIII uma nova visão na concepção de família surge na sociedade a partir das mudanças econômicas, sociais e culturais. Os pais passam a se preocupar mais com a vida das crianças em seus vários aspectos: educativos, saúde/higiene, trabalho, lazer etc. Porém, estas preocupações só estão presentes na classe burguesa, as demais crianças permanecem voltadas para o trabalho como forma de sobrevivência. $\mathrm{O}$ atendimento dado aos filhos dos ricos é de qualidade e aos filhos dos pobres é de caráter disciplinar (MENEZES, 2012).

A atenção para a questão social da criança se dá depois da segunda Guerra Mundial. Nasce neste contexto uma nova concepção de infância, a criança como sujeito de direitos. A Organização das Nações Unidas (ONU) em 20 de novembro de 1959 apresenta à nação o documento Declaração Universal dos Direitos da Criança com o objetivo de assegurar à criança uma infância feliz, as condições de sobrevivência e o exercício do seu direito de cidadania. Este documento é fiscalizado pelo Fundo das Nações Unidas para a Infância (UNICEF) e faz um apelo aos pais, às autoridades, ao poder público, aos Governos Nacionais, às ONGs e demais envolvidos com a criança para que façam valer este direito. $\mathrm{O}$ referido documento elege dez princípios fundamentais para garantir os direitos infantis (MENEZES, 2012). 
Na contemporaneidade, o sentimento de infância, segundo Kramer (2006), está relacionado às ações dos adultos. Por um lado, a criança é percebida como um ser ingênuo, inocente e gracioso e por outro é vista como um ser imperfeito e incompleto, que necessita ser educada. Neste sentido, a família passa a assumir uma nova postura em relação à criança, surgindo na sociedade uma outra concepção de família. Este olhar lançado para a infância vai resultar numa dupla atitude dos adultos: preservar a criança da corrupção social mantendo sua inocência e fortalecêla desenvolvendo o seu caráter (MENEZES, 2008).

Daí surge a afirmativa de que todas as crianças são iguais, extraindo, a partir desse contexto, o conceito de criança como essência, desarticulada da existência. Essa concepção é fruto da organização social da classe dominante. Assim, destaca a referida autora: "Encarar a infância dentro da sociedade de classes significa que não existe "a" criança, mas sim indivíduos de pouca idade que são afetados diferentemente pela sua situação de classe social” (KRAMER, 2006, p. 18). É importante ressaltar que, na sociedade capitalista, com o pleno desenvolvimento industrial, a criança deixa o papel de produtor exercido no período feudalista para se tornar alguém que precisa de cuidado, de escola e de preparação para o futuro (MENEZES, 2008).

Atualmente, a Sociologia da Infância tem se destacado por apresentar discussões acerca das concepções de infância(s), da sua (in)visibilidade e dos direitos das crianças. O olhar lançado para criança na sociedade contemporânea é de um ser que pensa, imagina e age, portanto é um ser histórico, social e cultural em processo de formação. Faria e Finco (2011) corroboram dando maior visibilidade as crianças, destacando-as como protagonistas sociais e valorizando as culturas infantis. De acordo com as autoras é necessário compreendermos o espaço/tempo da infância e percebermos como as crianças estão ocupando este lugar na sociedade.

\section{As políticas públicas para a educação no campo: a conquista do espaço da educação infantil}


Não podemos analisar o contexto real de uma instituição de Educação do Campo sem fazermos uma reflexão sobre as políticas públicas criadas e ou implementadas visando o desenvolvimento desta realidade educacional. A política de valorização da Educação do Campo é recente em nosso país, principalmente, no tocante a Educação Infantil. As principais leis brasileiras não contemplam ou, apenas, fazem um rápido destaque a esta questão. Revisitando a Constituição Federal de 1988 não foi encontrado artigos que mencionem a Educação do Campo. No Estatuto da Criança e do Adolescente/1990, uma das grandes leis do Brasil, que assegura amparo e proteção à criança e ao adolescente, também, não faz referência a este tipo de educação. Porém, em seu artigo 53, ao visar o desenvolvimento da criança e o exercício da sua cidadania, preconiza no inciso $\mathrm{V}$, deste mesmo artigo, o direito à escola próxima da sua moradia, abrindo, nas entrelinhas, espaços para discussões futuras sobre a necessidade/importância da Educação do Campo para a criança pequena.

A Lei de Diretrizes e Bases da Educação Nacional, no 9.394/96, não trata da Educação do Campo. Não tem uma Seção específica para o assunto e nem discute nas Seções de Educação Infantil, Ensino Fundamental, Ensino Médio etc. No Capítulo II DA EDUCAÇÃO BÁSICA, o que consta é que os sistemas de ensino deverão promover adaptações para a população rural. Vale ressaltar que estas exigências legais, de modo geral, também não são cumpridas pelos municípios. Assim, reza o artigo 28: Na oferta da educação básica para a população rural, os sistemas de ensino promoverão as adaptações necessárias à sua adequação às peculiaridades da vida rural e de cada região especialmente [...].

O Plano Nacional de Educação/2001-2011 legisla nesta mesma direção. Não vislumbra a Educação do Campo e, sim, formas diferenciadas de organização das escolas para atender as especificidades da zona rural. Salientamos que estes objetivos estão traçados na Seção do Ensino Fundamental, mas na Seção da Educação Infantil, a questão não é discutida.

A passos muito lentos a Educação do Campo tem conquistado o seu espaço. Estamos percebendo que algumas políticas públicas têm influenciado, positivamente, na organização e sistematização das escolas do campo, ampliando a 
qualidade da educação. Diante da história e do contexto real da Educação do Campo, apresentando uma demanda grande de crianças do campo sem educação/cuidado, principalmente, nas áreas de reforma agrária, a sociedade civil organizada vem tomando consciência da importância de iniciar os debates sobre a Educação Infantil do campo.

Em 2002, com o reconhecimento das especificidades da população rural, tais como vida social própria, diversidade cultural, tempos e espaços do campo e a constituição da identidade da Educação do Campo, a Resolução CNE/CEB 1, de 03 de abril de 2002, institui as Diretrizes Operacionais para a Educação Básica nas Escolas do Campo, as quais consistem em um conjunto de princípios e procedimentos que orientam a Educação do Campo em consonância com as Diretrizes Curriculares Nacionais para a Educação Básica. Assim preconiza o artigo $2^{\text {o }}$ - Parágrafo único: "A identidade da escola do campo é definida pela sua vinculação às questões inerentes à sua realidade, ancorando-se na temporalidade e saberes próprios dos estudantes [...].

Em 2008, o Ministério da Educação abriu um processo de discussão acerca da temática, discussões estas que vão ganhando espaço e se intensificando cada vez mais. O MEC, numa ação coletiva com outros órgãos da sociedade como o Instituto Nacional de Colonização e Reforma Agrária (INCRA) e a Secretaria de Desenvolvimento Territorial (SDT) formam um Grupo de Trabalho Interministerial composto pelos representantes da Coordenação Geral de Educação do Campo (CGEC), da Coordenação Geral de Educação Infantil (COEDI), do Programa Nacional de Educação na Reforma Agrária (PRONERA), dentre outros, e elaboram três documentos importantes:

I. Diagnóstico da Educação Infantil no Campo (Coordenação Geral de Educação do Campo/SECAD);

II. Texto sobre Educação Infantil na Reforma Agrária (MDA/PPIGREINCRA/PRONERA);

III. Plano de Ação para a Educação Infantil no Campo (MEC-SECAD/CGEC e SEB/COEDI). 
O debate sobre a educação da criança do campo é ampliado, abrindo novas discussões e reuniões, com os diversos segmentos, com a intenção de solidificar o discurso sobre a infância no campo e elaborar propostas para construção de políticas públicas. A partir destes estudos foram definidos encaminhamentos fundantes para o desenvolvimento da Educação Infantil do Campo:

Levantamento da demanda de atendimento da Educação Infantil no Campo.

Identificação das experiências de Educação Infantil em desenvolvimento no Campo.

Desenvolvimento de estudos sobre o atendimento da Educação Infantil no Campo.

Elaboração de Referenciais Curriculares para a Educação Infantil do Campo.

Discussão e definição junto ao FNDE, sobre a necessidade de adequações do PROINFÂNCIA para instituições de Educação Infantil no Campo.

Formação de professores com especificidade do Campo.

Aquisição de material didático-pedagógico para o Campo, dentre outros.

Estes foram indicativos significativos para o avanço das políticas para a Educação Infantil do Campo, porém muitas destas ações não foram, ainda, implementadas a nível federal, como, por exemplo, os Referenciais Curriculares para a Educação Infantil do Campo. Ainda em 2008, a Resolução nº 2, de 28 de abril de 2008, estabelece diretrizes complementares, normas e princípios para o desenvolvimento de políticas públicas de atendimento da Educação Básica do Campo. Estas Diretrizes, em seu artigo $3^{\circ}$, deixam claro que as escolas para a população rural devem estar situadas nas próprias comunidades das crianças e a organização do ensino precisa atender suas várias formas de produção da vida, ou seja, contemplar a diversidade. Outro ponto de destaque é o impedimento de classes multisseriadas na Educação do Campo.

Em 2009, através da Resolução CNE/CEB 05/2009, foi publicado o documento das Diretrizes Curriculares Nacionais para a Educação Infantil (DCNEI), fazendo um destaque extremamente importante acerca da proposta pedagógica, da valorização e do respeito à educação da criança do campo. Assim reza o artigo $8^{\circ}$, parágrafo $3^{\circ}$ :

Art. $8^{0}(\ldots)$

$\S 3^{\mathrm{o}}$ As propostas pedagógicas para a Educação Infantil das crianças filhas de agricultores familiares, extrativistas, pescadores artesanais, ribeirinhos, assentados e acampados da reforma agrária, quilombolas, caiçaras, povos da floresta, devem: 
I - reconhecer os modos próprios de vida no campo como fundamentais para a constituição da identidade das crianças moradoras em territórios rurais.

$[\ldots]$.

Em 2010, foi realizado em Brasília o I Seminário Nacional de Educação Infantil do Campo, envolvendo representantes do CNE, CONEC, CONTAG, MST, UNCME, UNDIME, universidades, comitês, fóruns, pesquisadores e profissionais da educação, dentre outros. Os encaminhamentos mais relevantes direcionados à política nacional para a Educação Infantil do Campo foram: trabalho pedagógico, espaço físico, formação inicial e continuada, financiamento, pesquisas, valorização dos profissionais e articulações intersetoriais. Este seminário anuncia um avanço no processo de democratização da Educação do Campo.

Nesse contexto, é necessário e urgente que sejam reconhecidos, pelos municípios, os direitos da criança do campo de viver a sua infância com dignidade, de frequentar instituições escolares de qualidade, de serem produtores de cultura e de se desenvolverem de forma global e integral. Assim, asseveram Silva e Pasuch (2011, p. 2):

Como todas as crianças brasileiras, são sujeitos de direitos! Elas têm garantido o direito de freqüentar creches e pré-escolas com qualidade! Direito a educação infantil no campo, oferecida perto da sua casa, na sua comunidade. Direito de serem transportadas com dignidade e de não percorrerem longos trajetos entre a casa e a creche/pré-escola. Direito de conviverem com outras crianças, de terem acesso a espaços, materiais, brincadeiras e tempos organizados para que vivam plenamente suas infâncias e para que se encantem com as descobertas e os conhecimentos que a humanidade já fez e produziu e que seu grupo (re)cria nas interações cotidianas entre seus membros, adultos e crianças [...].

O Plano Nacional de Educação/2014-2024 no que se refere a Educação Infantil do Campo destaca na Meta 1, Estratégia 1.10:

Fomentar o atendimento das populações do campo e das comunidades indígenas e quilombolas na educação infantil nas respectivas comunidades, por meio do redimensionamento da distribuição territorial da oferta, limitando a nucleação de escolas e o deslocamento de crianças, de forma a atender às especificidades dessas comunidades, garantido consulta prévia e informada.

Diante da legislação brasileira e das políticas públicas criadas para a Educação do Campo, podemos afirmar que, legalmente, temos avançado nesta direção. 
Porém, a conquista deste espaço no contexto real ainda é considerada muito

pequena. É preciso criar mecanismos que superem as barreiras impostas pelo poder público, direcionar mais investimentos para o campo, ter vontade política e compromisso com esta realidade, implementar políticas e construir novas metas para a Educação do Campo, levando em consideração os princípios da Educação do Campo e a visibilidade da infância.

\section{Procedimentos metodológicos}

Para a realização desta pesquisa, uma vez que esta é uma atividade que envolve planejamento, organização e sistematização, com vistas à produção de novos conhecimentos, foi adotada a pesquisa qualitativa, buscando um referencial teórico-metodológico que permitiu compreender a complexidade do fenômeno, fundamentado na abordagem fenomenológica e no método etnográfico. Foi utilizado como opção metodológica qualitativa o estudo de caso. A pesquisa foi realizada em uma instituição de Educação do Campo de um município baiano. A intenção foi analisar intensamente o contexto real, visando descrever, compreender e interpretar o fenômeno em estudo.

Como a opção metodológica desta pesquisa é o estudo de caso, para fortalecer a base teórico-metodológica da pesquisa foi realizado, também, o estudo bibliográfico e documental, pois são fundamentais ao estudo de caso e oportunizam segurança aos achados da pesquisa. Foi empregada na pesquisa a técnica da coleta e seus respectivos instrumentos: observação, entrevista semi-estruturada e grupo focal. Estes instrumentos foram aplicados com as professoras, a diretora e a coordenadora pedagógica da instituição educativa.

Participou também da pesquisa a Assessora Técnico-Pedagógica de Educação Infantil do Campo do município. A técnica da análise de conteúdo foi realizada de forma densa e fundamentada com o objetivo de assegurar a qualidade da pesquisa. De acordo com Bardin (2009), esta técnica busca interpretar os achados levando em consideração a objetividade e a subjetividade, ou seja, ir além do 
aparente, ler o que não está escrito e ver o não observável. Para atingir estes objetivos foram aplicados os instrumentos, unidades de significação e categorização.

\section{Discussão e resultados: uma análise do contexto real}

O município da pesquisa, apesar de desenvolvido e com alguns avanços na área educacional, apresenta uma realidade, ainda, crítica em relação à Educação do Campo. De acordo com a Assessora Técnico-pedagógica da Educação do Campo, muito já foi feito pelas escolas do campo, porém, as dificuldades e os entraves são grandes, necessitando de um maior investimento nesta direção. Assim, destaca a referida assessora:

- São inúmeras as dificuldades encontradas para a realização do trabalho escolar no campo. A educação do campo fica sempre à margem.

- As escolas em fazendas são casas de trabalhadores cedidas ao município pelos proprietários para serem utilizadas como escola. A parceria para a reforma é difícil, o município faz apenas pequenos reparos.

- Temos problemas de diversas naturezas. Por exemplo, temos o PDDE que abarca reformas escolares, mas as escolas do campo estão em propriedades particulares. Como fazer a reforma? Como ter prédio próprio em uma fazenda?

Os depoimentos da Assessora Técnico-pedagógica da Educação do Campo são coerentes com a realidade analisada. A escola é uma casa de fazenda improvisada e que, de fato, falta investimento no espaço físico. A estrutura não é adequada para uma escola, às salas de aula são pequenos cômodos, um dos espaços possui passagem para saída da escola por dentro da classe. A sala de direção só tem uma mesa para ser utilizada pela diretora, coordenadora pedagógica e secretária, mesmo que tivesse outra mesa não caberia na sala. Além do espaço pequeno, o mobiliário da classe das crianças de 04 anos chama a atenção. São mesas rústicas de madeira forradas com plástico e cadeiras plásticas infantis, porém não adequadas para sala de aula. No depoimento da professora foi esclarecido que estes móveis foram emprestados pela coordenadora, pois as crianças pequenas usavam carteiras grandes. Esta situação já tem anos e até hoje o problema não foi resolvido. 
A realidade do campo, no município pesquisado, é de escolas multisseriadas desde a Educação Infantil. Das 33 escolas no campo, apenas 17 escolas trabalham com turmas separadas e só as escolas maiores têm turmas específicas de Educação infantil atendendo a pré-escola. Ainda neste sentido, acrescenta a Assessora Técnico-pedagógica no grupo focal: “Um professor para atender as diversas idade/série. Um diretor, quando tem, exerce várias funções, quando não, o próprio professor realiza todas as atividades: faxineiro, merendeiro, porteiro, professor, coordenador, diretor etc".

É importante salientar que no município não existe creches no campo. Diante destes dados surge um sério questionamento: Como um município deste porte, com uma demanda latente, pode não atender as crianças de 0 a 3 anos, filhos e filhas de mães trabalhadoras do campo? A Assessora Técnico-pedagógica deposita suas esperanças de mudanças na Educação do Campo, de modo geral, nas Diretrizes Curriculares para a Educação do Campo. Acredita que a partir daí novas políticas serão criadas e implementadas pelo município.

As instituições do campo do município trabalham com o Programa Escola Ativa, mas como a proposta educacional do município é de Ciclos de Aprendizagem, algumas escolas são Cicladas. É importante ressaltar, ainda, que o objeto da Escola Ativa é o ensino fundamental e não a Educação Infantil. De acordo com a assessora, é feita uma parceria com a Assessoria Técnico-pedagógica de Educação Infantil da zona urbana para organização do trabalho pedagógico e capacitação dos professores de Educação Infantil, ou seja, as atividades planejadas para a zona urbana são estendidas para os profissionais do campo. Esta organização do ensino é impraticável, é necessária e urgente uma política de redimensionamento da proposta pedagógica da educação do campo no município. Como assessorar e alimentar a esta diversidade curricular? É preciso um trabalho voltado para as especificidades do campo e para os interesses da população rural.

De acordo com a assessora, para facilitar o trabalho pedagógico das 33 escolas foi feito um trabalho de nucleação, utilizando o critério da proximidade. Cada coordenador pedagógico realiza o seu trabalho em quatro ou cinco escolas nucleadas. Existem no campo três escolas grandes, estas possuem, cada uma, um 
coordenador. Este é o caso da escola pesquisada. Difícil é imaginar um coordenador assumindo o trabalho pedagógico em cinco escolas diferentes. Como acompanhar a gestão do processo educacional? Como orientar a prática pedagógica? Como fazer o percurso de uma escola para outra? Em quanto tempo?

A instituição escolar está inserida num contexto democrático e participativo. A equipe gestora trabalha em parceria com seus pares e com a comunidade, visando o desenvolvimento global das crianças através de uma boa articulação com a família e da interação com a comunidade local. As professoras têm consciência de que a forma de gestão e a participação são fatores essenciais no desenvolvimento efetivo do trabalho pedagógico. No grupo focal estas afirmativas são reforçadas pelas referidas professoras: " $\mathrm{Na}$ nossa escola, a gestora trabalha de acordo com os princípios da gestão democrática. Investe-se no melhor para o aluno. Temos autonomia. As decisões são tomadas em grupo, até o pessoal de apoio participa. Os pais participam e ajudam”.

Mesmo com todas as dificuldades estruturais o trabalho é realizado com muita dedicação, prazer e compromisso por parte de todos os envolvidos. Tudo é feito coletivamente. A diretora e a coordenadora são muito dinâmicas e contam com o apoio dos demais. Muito desta organização foi conseguido com esforços próprios, gincana, feira de cacareco, venda de tortas, cachorros-quente etc. Esta é verdadeiramente uma equipe articulada. Existe um excelente relacionamento com a comunidade. Quando a escola precisa de algo, a comunidade está sempre pronta para socorrê-la. A escola é gerida com a participação do Conselho Escolar composto por um presidente e um vice, dois professores, dois alunos, dois pais e dois funcionários.

De acordo com as Diretrizes Complementares de 2008, a Educação do Campo deverá oferecer uma prática pedagógica de qualidade, respeitando as diferentes formas de produção, as características peculiares do campo, os tempos e espaços da criança, os saberes próprios, o exercício da cidadania, a justiça social, a sustentabilidade ecológica, a humanização do homem, a solidariedade, o desenvolvimento da consciência individual e coletiva, a formação do cidadão crítico e atuante.

Rev. Caminhos da Educação: diálogos, culturas e diversidades, Teresina, v. 1, n. 3, p. 143165, jan/abr. 2020 
A prática pedagógica das professoras de Educação Infantil do Campo da instituição pesquisada é dinâmica, criativa e reflexiva. Mesmo com as dificuldades encontradas, como, por exemplo, a questão espacial e recursos didáticos, as professoras planejam e organizam o seu trabalho com compromisso e responsabilidade. Como as salas são muito pequenas, as educadoras aproveitam todo o espaço para articular com os processos de ensino e aprendizagem. Em um cantinho da sala é colocado um pequeno tapete com brinquedos e livros de história, tornando assim o lugar preferido e disputado pelas crianças. O espaço é tão minúsculo que só comporta duas ou três crianças. Outra forma de aproveitar bem o espaço é a utilização das portas dos armários com o alfabeto, os numerais, as regras educativas tais como: com licença, desculpe, por favor etc. O objetivo é oferecer um espaço de aprendizagem agradável para as crianças e, ao mesmo tempo, estimulante, produtivo, gerador do conhecimento.

Os processos de ensino e aprendizagem ocorrem de forma integral, processual e dinâmico. As professoras acompanham individualmente o desenvolvimento infantil observando os aspectos cognitivo, motor, afetivo e emocional da criança. Mesmo em uma sala pequena, com 26 crianças (situação extremamente crítica), a professora está sempre atenta às ações dos alunos: a realização das atividades, a postura, o desenvolvimento da leitura e da escrita. Vale ressaltar que as crianças participam ativamente do processo são alegres e comunicativas e demonstram interesse em aprender. O que chama bastante atenção na escola pesquisada é a prática da leitura. Todos valorizam bastante o desenvolvimento do ato de ler. Mesmo não possuindo uma biblioteca na instituição, as professoras lançam mão de diversas estratégias para incentivar as crianças à leitura: trabalhos com poemas, músicas, jornais, histórias em quadrinho são feitos pelas crianças e expostos em varal.

Nesse cenário observa-se que há um diálogo íntimo entre o desenvolvimento da criança e o processo de aprendizagem. A escola luta para manter a sua qualidade ancorada na abordagem sociointeracionista de Vygotsky, compreendendo que desenvolver e aprender não são processos isolados, sem comunicação, fragmentados. Requer interação, relação interpessoal e envolvimento. 
Grosbaum e Davis (2001, p. 19) colaboram destacando: “A aprendizagem estimula e fomenta processos de desenvolvimento que, uma vez realizados, criam novas possibilidades de aprendizagem".

A instituição é cercada por uma área verde. Tem um espaço maior que é considerado um campo de futebol para as crianças. Porém, não tem proteção, travas, redes, marcações, nada que indique um campo. As crianças brincam e se divertem bastante, mesmo quando não estão em horário de aula, aparecem para o jogo. É importante ressaltar que nesta área não há nenhuma plantação de hortas e canteiros cultivados pelas crianças. Senti falta de uma maior articulação do trabalho educativo com a diversidade do campo, pontos chaves para a educação do campo. Assim, corrobora Silva e Pasuch (2011, p. 1):

\begin{abstract}
Mas, também é importante considerar que as crianças do campo possuem seus próprios encantos, modos de ser, de brincar e de se relacionar. As crianças do campo têm rotinas, experiências estéticas e éticas, ambientais, políticas, sensoriais, afetivas e sociais próprias. Os tempos de plantar e de colher, os ciclos de produção, de vida e de morte, o tempo das águas e estiagem, as aves e bichos do mato, dos mangues, dos pantanais, a época de reprodução dos peixes, aves, pássaros e outros animais, o amanhecer e o entardecer, o tempo de se relacionar com os adultos e crianças, tudo isso marca possibilidades diferenciadas de viver a infância [...].
\end{abstract}

Os docentes devem ser capacitados, especificamente, para trabalhar com a educação do campo. De acordo com Silva e Pasuch (2011, p. 12): “Ser professor da educação infantil do campo requer a experimentação, o gosto pela terra, o contato direto com a terra, a vivência e a sensibilidade com a água, rios, mananciais, nascentes". Requer criatividade, curiosidade, pesquisas e observações das crianças. No planejamento da prática pedagógica devem estar presentes as experiências e vivências das crianças, o seu saber/fazer cotidiano. Atividades como piqueniques embaixo de árvores, excursões pelo campo, torneios de futebol, plantação de hortas, banho de cachoeira, dramatizações, produção de artesanatos, apresentação cultural etc. promovem o desenvolvimento infantil e facilitam o processo de aprendizagem, aproveitando bem os tempos e espaços da criança. As referidas autoras enriquecem as afirmativas acrescentando:

Construir esculturas de argila, brincar com sagu colorido, preparar o suco do lanche, construir brinquedos e instrumentos sonoros com produtos naturais, esculpir em frutas, preparar e ambientar os espaços para as atividades, construir cabanas com tecidos e folhas Rev. Caminhos da Educação: diálogos, culturas e diversidades, Teresina, v. 1, n. 3, p. 143165, jan/abr. 2020 
embaixo de árvores ou cantinhos descobertos pelas crianças, dramatizar histórias de tradição local, enfeitar-se de personagens regionais, conhecer fontes e nascentes, podem compor projetos na organização do tempo com as crianças [...] (SILVA e PASUCH 2011, p. 7).

Articular as políticas públicas, a gestão escolar e a prática pedagógica é o desafio das instituições infantis do campo com a finalidade de promover uma educação de qualidade baseada nos princípios da educação do campo, assegurando às crianças o direito a uma infância digna, humana e prazerosa. Silva e Pasuch (2011, p. 11) acrescentam: "Educar crianças do campo significa assumir o compromisso de garantir que as práticas junto às crianças lhes permitam viver suas infâncias com todas as potencialidades que a vida do campo oferece".

Para tanto, é preciso que as instituições do campo construam coletivamente um projeto político pedagógico que valorize a diversidade e as necessidades das crianças do campo e traduza a dinâmica da escola. É necessário envolver fortemente a família e a comunidade nas ações e decisões a serem tomadas. O professor precisa ressignificar seus conceitos e, também, ressignificá-los para as crianças. O município precisa se comprometer com a qualidade da educação do campo e fazer acontecer, na prática, as diretrizes e políticas criadas para este espaço educativo. Desta forma, se estará contribuindo com o desenvolvimento global da criança e construindo o processo de democratização da Educação Infantil do Campo.

\section{Considerações finais}

A Educação Infantil tem avançado gradativamente no campo científico, legal e educacional. Desde os anos de 1990, a criança passou, de forma mais ampla, a ser alvo das lutas políticas, sociais e educacionais. A infância e a criança têm sido objeto de muitos debates e estudos nas diversas áreas do conhecimento, não só da educação, como também da Psicologia, da Neurologia, da Sociologia, da Antropologia, dentre outras. O objetivo das ciências, de modo geral, é dar à criança o seu espaço social no mundo contemporâneo. É reconhecer na criança um membro da sociedade, com direitos e possibilidades de participar ativamente do processo, assumindo, assim, o seu papel de pequeno cidadão nos diferentes espaços.

Rev. Caminhos da Educação: diálogos, culturas e diversidades, Teresina, v. 1, n. 3, p. 143-162 165, jan/abr. 2020 
Os achados da pesquisa apontam que na Educação Infantil do Campo existe uma relação tímida entre as políticas públicas, a gestão, os sabres e a prática pedagógica. É esta articulação que assegura a qualidade do processo educativo das crianças do campo. Existe uma íntima relação entre a gestão escolar e a gestão da sala de aula e estas apresentam uma interdependência com as políticas públicas às quais se concretizam no saber/fazer do cotidiano pedagógico quando bem gerida pela equipe gestora da escola. A gestão democrática da educação vai se desvelando no cotidiano escolar através do diálogo contínuo entre a prática pedagógica e a prática administrativa entrecruzadas com as macropolíticas (nacional/global) educacionais e as micropolíticas (local). As necessidades e dificuldades emergidas do contexto escolar direcionam os caminhos a serem percorridos, contribuindo para o planejamento, avaliação e redimensionamento da gestão e da prática educativa e sinalizando a necessidade da construção/implementação de políticas públicas para a Educação Infantil do Campo.

Apesar dos esforços dos profissionais envolvidos na educação do campo, ainda está muito presente no município a distância entre as políticas públicas criadas para este espaço educacional e a implementação destas políticas, prejudicando a gestão, o trabalho pedagógico, a qualidade da aprendizagem das crianças e, consequentemente, impossibilitando a criança do campo viver a sua infância de forma digna. É preciso ampliar as discussões e as possibilidades de garantir os direitos pessoais, sociais, educacionais e políticos da criança do campo na sociedade contemporânea.

\section{Referências}

ARIÈS, Philippe. História Social da Criança e da Família. A escola deve envolver fortemente a família e a comunidade nas ações e decisões da escola. Rio de Janeiro: LTC, 1978.

BRASIL/MEC. Lei de Diretrizes e Bases da Educação Nacional. Lei no 9394, de 20 de dezembro de 1996. 
BRASIL. Estatuto da Criança e do Adolescente. Lei no 8.069/90, de 13 de julho de 1990. São Paulo: CBIA-SP, 1991.

BRASIL. Resolução CEB no 1, de 07 de abril de 1999. Institui as Diretrizes Curriculares Nacionais para a Educação Infantil. Disponível em: http://www.portal.mec.gov.br Acesso em: 26 fev. 2008.

BRASIL. Diretrizes Operacionais para a Educação Infantil. Brasília: MEC/SEF, 2000.

BRASIL. Diretrizes Operacionais para a Educação Infantil. Brasília: MEC/SEF, 2000.

BRASIL. Lei n ${ }^{\circ}$ 10.172, de 09 de janeiro de 2001. Aprova o Plano Nacional de Educação e dá outras providências. Disponível em: http://www.planalto.gov.br Acesso em 26 fev. 2008.

BRASIL. Lei no 13.005, de 25 de junho de 2014. Aprova o Plano Nacional de Educação (PNE) e dá outras providências. Disponível em: http://www.planalto.gov.br Acesso em 19 abril 2018.

BRASIL. Constituição Federal de 1988. Disponível em http://www.dji.com.br/constituicao_federal/cf205a214.htm Acesso em 05 ago. 2010.

BARDIN, Laurence. Análise do Conteúdo. São Paulo: Edições 70, 2009.

FARIA, Ana Lúcia Goulart de; FINCO, Daniela (orgs.). Sociologia da Infância no Brasil. Campinas, SP: Autores Associados, 2011.

GROSBAUM, Marta Wolak; DAVIS, Cláudia Leme Ferreira. Progestão: como promover o sucesso da aprendizagem do aluno e sua permanência na escola? Módulo IV, Brasília: CONSED - Conselho Nacional de Secretários de Educação, 2001.

KRAMER, Sônia. A política do Pré-escolar no Brasil: a arte do disfarce. São Paulo: Cortez, 2006.

MENEZES, Cláudia Celeste Lima Costa. A organização dos espaços de ensinar e aprender numa escola de educação infantil do município de Jequié - Bahia. Salvador: UFBA, 2008. (Dissertação de Mestrado)

MENEZES, Cláudia Celeste Lima Costa. Educação Infantil: a interseção entre as políticas públicas, a gestão educacional e a prática pedagógica - um estudo de caso no município de Itabuna - Bahia. Salvador: UFBA, 2012. (Tese de Doutorado)

SILVA, Ana Paula Soares da; PASUCH, Jaqueline. Orientações Curriculares para a Educação Infantil do Campo. Disponível em: portal.mec.gov.br. Acesso em 30 set. 2011.

VASCONCELLOS, Vera Maria Ramos de. (Org.) Educação da Infância: história e política. Rio de Janeiro: DP\&A, 2005. 
RECEBIDO: $15 / 01 / 2020$

APROVADO:03/03/ 2020
RECEIVED: $15 / 01 / 2020$

APPROVED: 03/03/ 2020
RECIBIDO: $15 / 01 / 2020$

APROBADO: 03/03/2020 